\title{
Bilateral loss of cortical SSEP responses is compatible with good outcome after cardiac arrest
}

\author{
Andreas Bender · Kaitlen Howell • Marcel Frey • \\ Ansgar Berlis • Markus Naumann • \\ Gernot Buheitel
}

Dear Sirs,

Global cerebral ischemia (GCI) following cardiac arrest (CA) is often associated with a poor prognosis and longterm disorders of consciousness. Bilateral absence of cortical responses of the median nerve somatosensory evoked potentials (SSEP) is believed to predict poor outcome with almost $100 \%$ specificity [1-4].

We report a case of a patient with good outcome despite repeatedly absent cortical SSEP responses and without hypothermia.

A 16-year-old student suffered CA while playing soccer. Cardiopulmonary resuscitation began within $3 \mathrm{~min}$. Initial rhythm analysis showed ventricular fibrillation (VF, Fig. 1a). Both pupils were dilated and unresponsive to light. After $25 \mathrm{~min}$ of resuscitation, stable cardiac output was reestablished and he was admitted to an intensive care unit. Despite the lack of sedative drugs, he was comatose.

\author{
A. Bender $(\bowtie) \cdot$ K. Howell $\cdot$ M. Frey \\ Department of Neurology, Therapiezentrum Burgau, \\ Dr.-Friedl-Str. 1, 89331 Burgau, Germany \\ e-mail: andreas.bender@med.uni-muenchen.de \\ A. Bender $\cdot$ K. Howell \\ Department of Neurology, Klinikum Grosshadern, \\ University of Munich, Munich, Germany \\ A. Berlis \\ Department of Diagnostic Radiology and Neuroradiology, \\ Zentralklinikum Augsburg, Augsburg, Germany \\ M. Naumann \\ Department of Neurology, Zentralklinikum Augsburg, \\ Augsburg, Germany \\ G. Buheitel \\ Department of Pediatrics, Zentralklinikum Augsburg, \\ Augsburg, Germany
}

The GCS motor score was three and pupils were reactive to light. Because of aspiration pneumonia, the patient was ventilated and sedation was started with propofol, midazolam, and fentanyl for $48 \mathrm{~h}$. Hypothermia was not induced, because this was only optional for children according to the 2005 European resuscitation council guidelines [5]. Neurological assessment after $72 \mathrm{~h}$ (with no sedation for the last 24) revealed a GCS of 5 (E1V1M3). At this time, median nerve SSEP were conducted in a specialized neurophysiology lab (>3000 recordings/year). N20 cortical responses were bilaterally absent (Fig. 1b). The EEG showed severe encephalopathy. Serum markers for neuronal damage were not examined. A brain CT scan after $96 \mathrm{~h}$ showed slight brain edema and obscuration of the caudate nucleus head (Fig. 1c).

Based on the lack of arousal and the unfavourable SSEP results, the parents were informed about the diagnosis of severe GCI and the nearly inevitable poor prognosis. Because of a myoclonic status of the diaphragm, he was treated with repeated single doses of barbiturates and muscle relaxants on days 4-7. Sedation was discontinued on day 7 , but again the patient failed to recover consciousness. On day 9, SSEP were repeated and again showed no signs of cortical N20 responses. He was extubated on day 12 . On day 27 , he was transferred to a specialized neurorehabilitation center in the minimally conscious state. He remained in inpatient rehabilitation for 7 months with constant improvement of neurological function. He was able to leave the rehabilitation facility on foot together with his mother (Fig. 1d). 3 years after cardiac arrest, the patient now lives at home with his parents (Barthel index 90/100 points). He rates his quality of life as $65 \%$ (EuroQol, ranging from 0 to $100 \%$ ). Dysarthria and fine motor control problems are his biggest limitations on participation in life. A mutation in the SCN5A-gene was 
Fig. 1 (a) Initial rhythm analysis with persistent ventricular fibrillation despite first shock with $200 \mathrm{~J}$.

(b) Median nerve SSEP on day 3 after cardiac arrest with bilateral absence of cortical N20 responses. Placement of electrodes was in supraclavicular fossa, cervical $\mathrm{C} 7$ and $\mathrm{C} 2$, primary sensory cortex $\left(\mathrm{C}^{\prime}\right.$ or $\left.\mathrm{C}^{\prime}\right)$, and common reference at $\mathrm{FpZ}$, according to 10-20-system. Each lane shows two superimposed SEP recordings, consisting of 400 averages each. Note the good technical quality with reproducible peripheral N9 and N13 responses. (c) Native cerebral CT scan on day 4 showing slight brain edema as well as partial loss of signal in the head of the caudate nucleus. (d) Patient photographs showing him climbing stairs (assisted) 3 months post cardiac arrest (left), starting to enjoy soccer again (middle), and leaving the rehabilitation hospital 8 months after cardiac arrest (right)
A

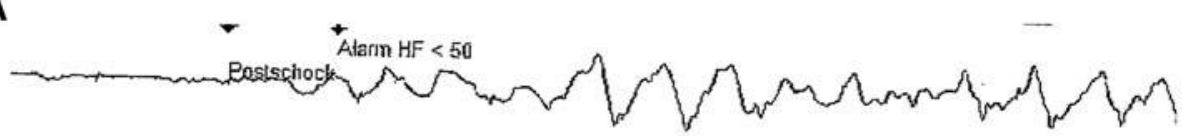

B
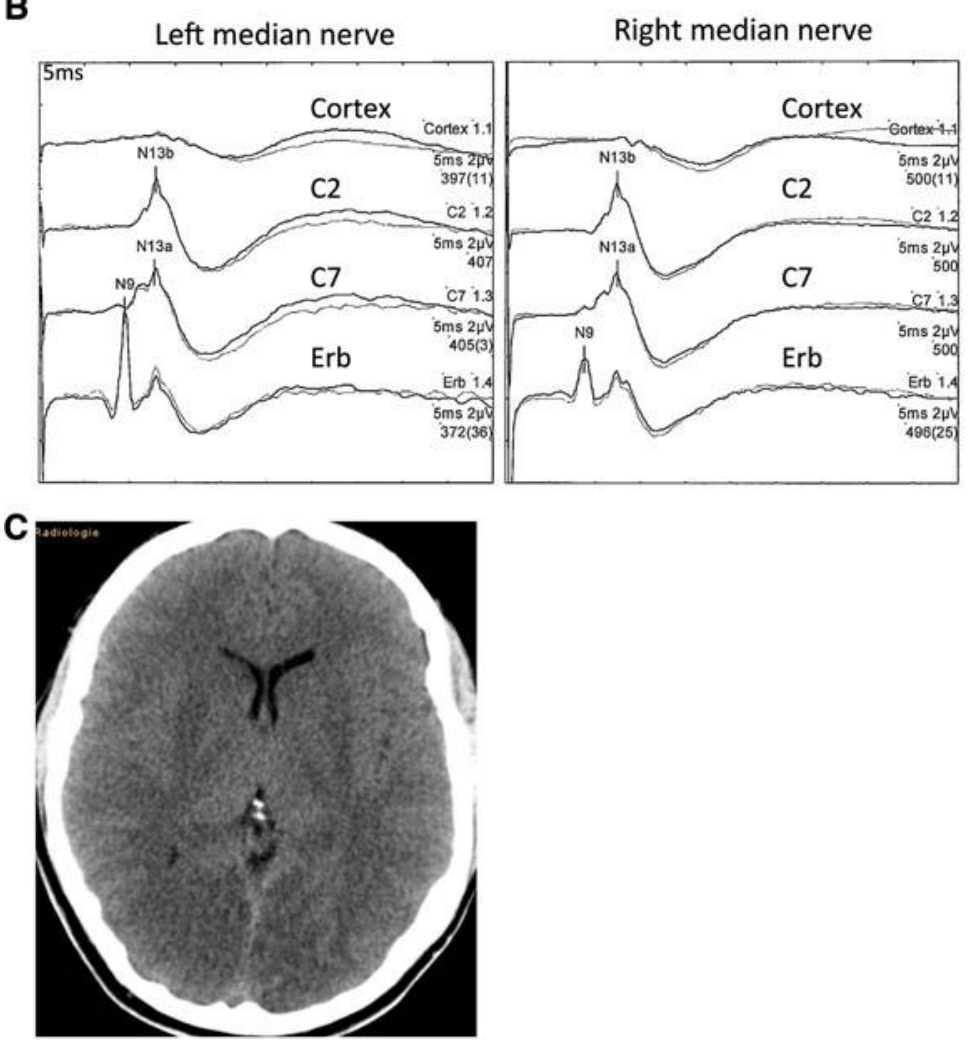

D

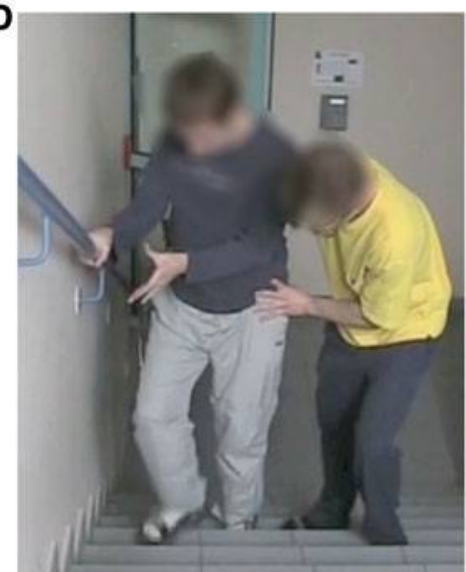

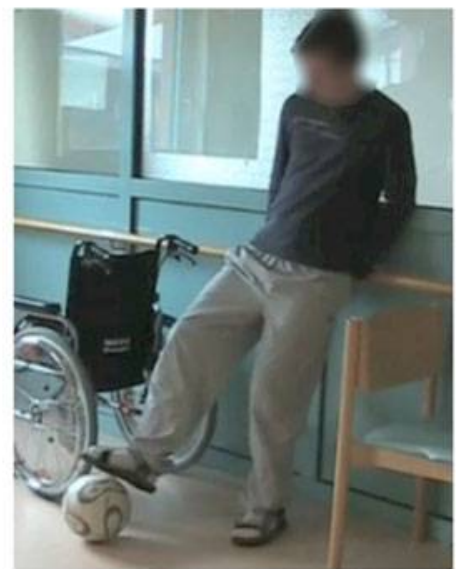

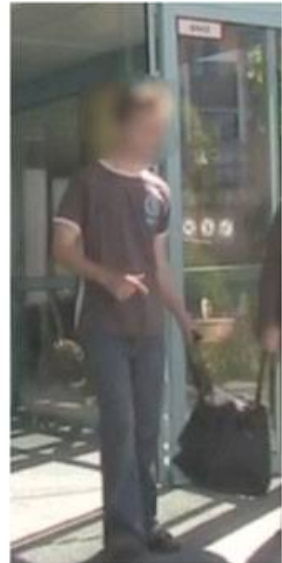

found as the cause for cardiac arrhythmias and he received an internal defibrillator device.

According to international guidelines, bilateral loss of SSEP N20 cortical responses virtually rules out good prognosis with false positive rates between $0 \%$ and $0.7 \%$ $[2,4,6]$. This single finding in the setting of a comatose CA survivor is therefore often used as an argument to withdraw life-sustaining therapy (LST) [7]. Some uncertainty remains whether therapeutic hypothermia or stimulus rate may impact SSEP prognostic accuracy $[8,9]$. Nonetheless, even up-to-date prospective studies employing hypothermia in all patients found the specificity of bilateral absence of N20 to be $100 \%$ [10].

To our knowledge, this is the first well-documented case with good functional outcome despite two malignant SSEP results and lack of hypothermia following CA. If the 
treating neurointensivists had followed published guidelines, this young man probably would have died after LST withdrawal. This case highlights the potential danger of self-fulfilling prophecies in prognostication of comatose CA survivors and shows the dilemma of presumed $100 \%$ specificity-parameters.

Acknowledgments This work was supported by the ZNS Hannelore-Kohl-Stiftung with a grant to A.B. (\#2011013).

Conflicts of interest The authors declare that they have no conflict of interest.

Ethical standard All human studies must state that they have been approved by the appropriate ethics committee and have therefore been performed in accordance with the ethical standards laid down in the 1964 Declaration of Helsinki.

\section{References}

1. Young GB (2009) Clinical practice. Neurologic prognosis after cardiac arrest. N Engl J Med 361(6):605-611. doi:10.1056/NEJ Mcp0903466

2. Wijdicks EF, Hijdra A, Young GB, Bassetti CL, Wiebe S (2006) Practice parameter: prediction of outcome in comatose survivors after cardiopulmonary resuscitation (an evidence-based review): report of the Quality Standards Subcommittee of the American Academy of Neurology. Neurology 67(2):203-210
3. Zandbergen EG, Hijdra A, Koelman JH, Hart AA, Vos PE, Verbeek MM, de Haan RJ (2006) Prediction of poor outcome within the first 3 days of postanoxic coma. Neurology 66(1): $62-68$

4. Zandbergen EG, Koelman JH, de Haan RJ, Hijdra A (2006) SSEPs and prognosis in postanoxic coma: only short or also long latency responses? Neurology 67(4):583-586

5. Biarent D, Bingham R, Richmond S, Maconochie I, Wyllie J, Simpson S, Nunez AR, Zideman D (2005) European resuscitation council guidelines for resuscitation 2005. Section 6. Paediatric life support. Resuscitation 67(Suppl 1):S97-133. doi:10.1016/j. resuscitation.2005.10.010

6. Bouwes A, Binnekade JM, Kuiper MA, Bosch FH, Zandstra DF, Toornvliet AC, Biemond HS, Kors BM, Koelman JH, Verbeek MM, Weinstein HC, Hijdra A, Horn J (2012) Prognosis of coma after therapeutic hypothermia: a prospective cohort study. Ann Neurol 71(2):206-212. doi:10.1002/ana.22632

7. Geocadin RG, Buitrago MM, Torbey MT, Chandra-Strobos N, Williams MA, Kaplan PW (2006) Neurologic prognosis and withdrawal of life support after resuscitation from cardiac arrest. Neurology 67(1):105-108

8. Leithner C, Ploner CJ, Hasper D, Storm C (2010) Does hypothermia influence the predictive value of bilateral absent N20 after cardiac arrest? Neurology 74(12):965-969. doi:10.1212/ WNL.0b013e3181d5a631

9. Robinson LR, Micklesen PJ (2010) Does stimulus rate matter when performing somatosensory evoked potentials for coma patients? Neurocrit Care 12(1):69-73. doi:10.1007/s12028009-9191-2

10. Rossetti AO, Oddo M, Logroscino G, Kaplan PW (2010) Prognostication after cardiac arrest and hypothermia: a prospective study. Ann Neurol 67(3):301-307. doi:10.1002/ana.21984 